\title{
Three-Dimensional Bioprinting Strategies for Tissue Engineering
}

\author{
Yu Shrike Zhang, ${ }^{1,2,3}$ Rahmi Oklu, ${ }^{1,4}$ Mehmet Remzi Dokmeci, ${ }^{1,2,3}$ \\ and Ali Khademhosseini ${ }^{1,2,3,5,6}$ \\ ${ }^{1}$ Biomaterials Innovation Research Center, Division of Biomedical Engineering, Department of Medicine, \\ Brigham and Women's Hospital, Harvard Medical School, Cambridge, Massachusetts 02139 \\ ${ }^{2}$ Harvard-MIT Division of Health Sciences and Technology, Massachusetts Institute of Technology, \\ Cambridge, Massachusetts 02139 \\ ${ }^{3}$ Wyss Institute for Biologically Inspired Engineering, Harvard University, Boston, Massachusetts 02115 \\ ${ }^{4}$ Division of Vascular \& Interventional Radiology, Mayo Clinic, Scottsdale, Arizona 85259 \\ ${ }^{5}$ Department of Bioindustrial Technologies, College of Animal Bioscience and Technology, Konkuk University, \\ Hwayang-dong, Gwangjin-gu, Seoul 143-701, Republic of Korea \\ ${ }^{6}$ Department of Physics, King Abdulaziz University, Jeddah 21569, Saudi Arabia \\ Correspondence: alik@bwh.harvard.edu
}

Over the past decades, many approaches have been developed to fabricate biomimetic extracellular matrices of desired properties for engineering functional tissues. However, the inability of these techniques to precisely control the spatial architecture has posed a significant challenge in producing complex tissues. 3D bioprinting technology has emerged as a potential solution by bringing unprecedented freedom and versatility in depositing biological materials and cells in a well-controlled manner in the 3D volumes, therefore achieving precision engineering of functional tissues. In this article, we review the application of 3D bioprinting to tissue engineering. We first discuss the general strategies for printing functional tissue constructs. We next describe different types of bioprinting with a focus on nozzle-based techniques and their respective advantages. Finally, we summarize the limitations of current technologies and propose challenges for future development of bioprinting.

Tisis ssue engineering seeks to restore tissue function through an interdisciplinary approach based on materials science, mechanics, biology, medicine, and engineering. Over the past decade, the field has seen tremendous advancements with the advent of various techniques for fabrication of biomimetic tissues and organs. The biomaterials, typically processed into 3D scaffolds featuring well-defined architecture, assume an indispensable role in tissue regeneration by functioning as viable mimics of extracellular matrices (ECMs) for cells to remodel (Hutmacher 2001; Ma 2004; Owen and Shoichet 2010; Zhang et al. 2013; Zhang and Xia 2015). The scaffolds, when formed in different shapes, structures, porosities, connectivity, bio-

Editor: Joseph P. Vacanti

Additional Perspectives on Tissue Engineering and Regenerative Medicine available at www.perspectivesinmedicine.org

Copyright (C) 2018 Cold Spring Harbor Laboratory Press; all rights reserved; doi: 10.1101/cshperspect.a025718

Cite this article as Cold Spring Harb Perspect Med 2018;8:a025718 
Y.S. Zhang et al.

activity, and degradation kinetics, may suit for desired applications (Freed et al. 2009; Zhang et al. 2013; Zhang and Xia 2015). The concept of microengineering has also been proposed based on the bottom-up approach (Nichol and Khademhosseini 2009; Leijten et al. 2015), in which microscale building units containing desired properties are assembled in a predefined manner to allow for the construction of larger tissue blocks, by means of complementary shapematching ( $\mathrm{Du}$ et al. 2008, 2011) or DNA-enabled assembly (Qi et al. 2013; Todhunter et al. 2015). However, none of these approaches confer precisely defined architecture in the native tissues, thus likely resulting in limited reproducibility and therefore impaired quality of the engineered tissues.

On the contrary, the 3D printing technology, initially introduced in 1986 by Charles W. Hull in the form of stereolithography (Hull 1986), has been widely applied to reproducibly manufacture objects with complex geometries and architecture in areas such as home, design, art, and science (Allard et al. 2005; Malone and Lipson 2007; Symes et al. 2012). However, the potential of its translation to tissue engineering has only come to the attention of the community not long ago (Murphy and Atala 2014), as a potent alternative to preexisting techniques. In $3 \mathrm{D}$ bioprinting, the biomaterials, usually containing embedded bioactive molecules and/or cells, which together are referred to as the "bioink," are processed layer-by-layer following desired patterns as preprogrammed by the printer (Malda et al. 2013; Murphy and Atala 2014). Such a method empowers unprecedented precision through the robotic dispensing of the bioink, thus allowing for reproducible fabrication of biological tissues with minimum aberration in terms of shape, architecture, structure, and, ultimately, functionality. The entire process of bioprinting is automated, necessitating the absence of human operators to possibly enable high-throughput tissue manufacturing.

To date, 3D bioprinting has evolved into a set of different techniques encompassing the needs for fabrication of a variety of tissue types: sacrificial bioprinting has been developed to produce tissue blocks encapsulating interconnected hollow channels simulating the vascular network; embedded bioprinting was innovated for direct printing of 3D structures; and multimaterial bioprinting enables the production of complex tissues in which multiple ECMs, cell types, and/or gradients are present. These approaches can be further scaled up by the use of nozzle arrays to rapidly bioprint large tissues or simultaneously bioprint hundreds and thousands of smaller tissue units.

In this article, we review the application of $3 \mathrm{D}$ bioprinting to tissue engineering. We first discuss the general strategies for printing functional tissue/organ constructs. We then describe different types of bioprinting with a focus on nozzle-based techniques and their respective advantages. Finally, we summarize the limitations of current technologies and propose challenges for future development of bioprinting.

\section{GENERAL CONSIDERATION OF BIOPRINTING}

Figure 1 depicts the general step-wise procedure for fabricating functional tissues and organs enabled by 3D bioprinting. The initial steps involve the digital design principles of the tissues to be bioprinted. The advantage of the bioprinting process cannot be appreciated without proper designs that precisely recapitulate the complexity and often heterogeneous properties of the functional tissues. Noninvasive medical imaging modalities, such as X-ray computed tomography (CT) (Mankovich et al. 1994), magnetic resonance imaging (MRI) (Gering et al. 2001), optical coherence tomography (OCT) (Huang et al. 1991), and photoacoustic tomography (PAT) (Wang 2009; Wang and $\mathrm{Hu} 2012$ ), provide excellent volumetric information on the shape, structure, architecture, and even function across multiple levels from molecules and cells to ECMs and tissues. These details can then be readily imported into a computer to render the full set of information available to the bioprinter via meticulously conducted mathematical modeling and computer-aided designs, to determine how the tomographic properties and functions of the final tissues 

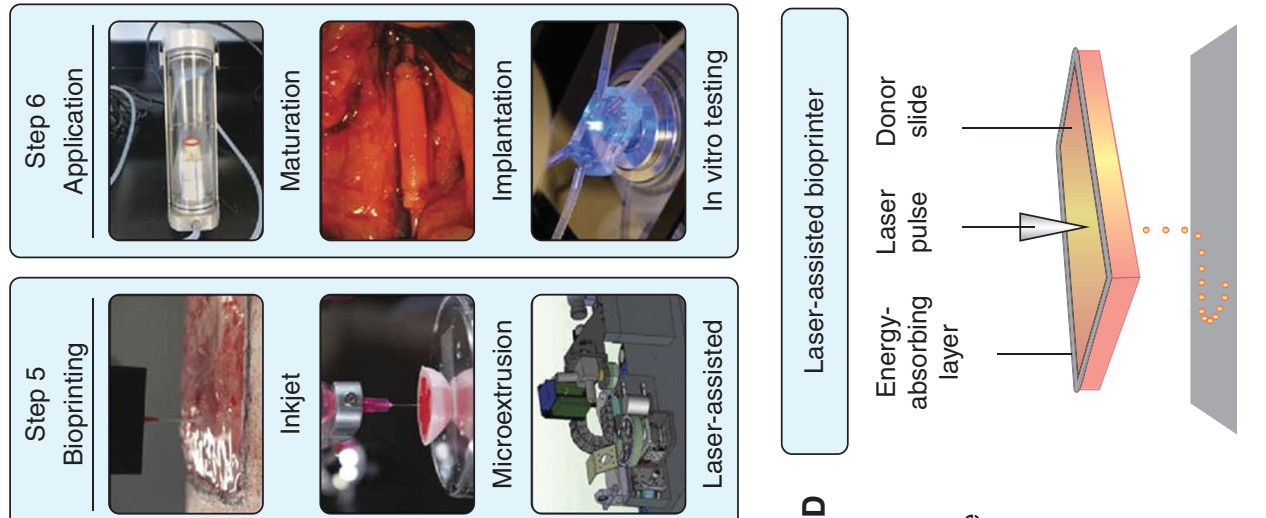

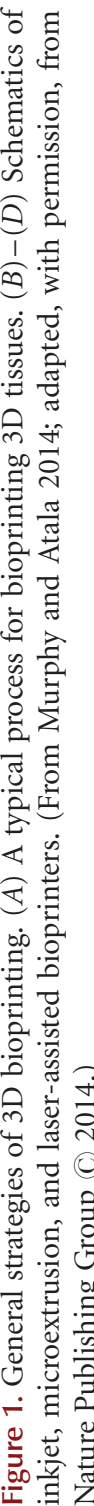
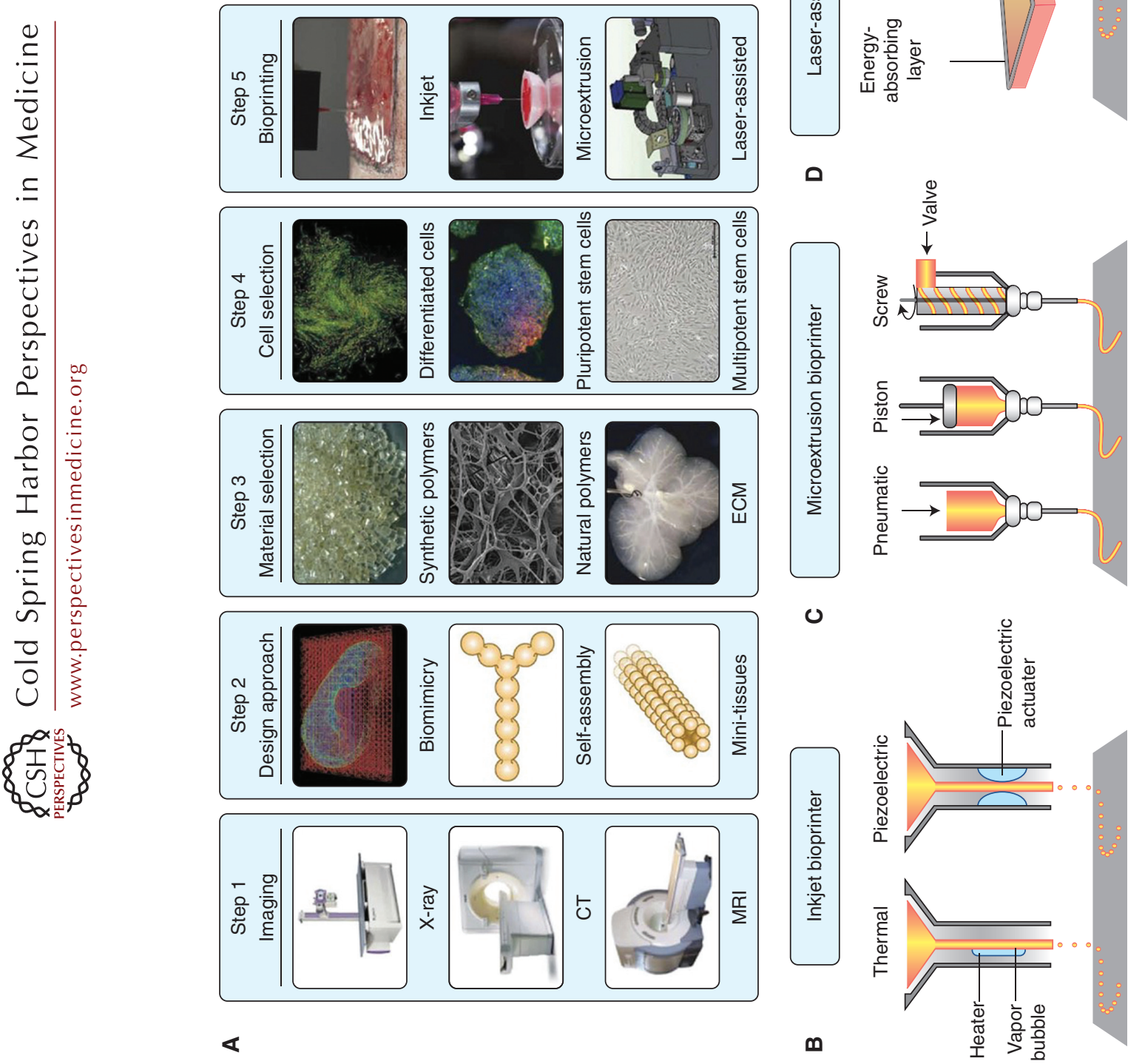

$\varangle$

$\boldsymbol{m}$ 
Y.S. Zhang et al.

will be reproduced to mimic their counterparts in vivo (Michalski and Ross 2014; Murphy and Atala 2014).

The procedure then follows by the selection of the bioinks, which include two critical components (i.e., the biomaterials as well as the cells). Similar to the ECMs in the native tissues, the biomaterials play a major role in supporting the attachment, proliferation, and function of embedded cells. The biomaterials can be programmed to possess degradation profiles that match the time required for tissue regeneration (Freed et al. 1994). Functionalization of the biomaterials with bioactive molecules, including cell-adhesion peptides (e.g., fibronectin, laminin, and RGD) (Hoffman 2012; Liu et al. 2012), growth factors (Richardson et al. 2001; Jeon et al. 2005; Martino et al. 2013), and responsive moieties (e.g., protease-sensitive linkers) (Lutolf et al. 2003; Khetan et al. 2013; Purcell et al. 2014) further brings extended capability to these biomimetic matrices in precise manipulation of cell behaviors that promote the formation of functional tissues. Both synthetic polymers such as poly(lactic-co-glycolic acid) (PLGA) (Pan and Ding 2012), polycaprolactone (PCL) (Hutmacher 2001), and poly(sebacateco-glycerol) (PGS) (Wang et al. 2002) as well as naturally derived biomaterials such as collagens (Cen et al. 2008; Glowacki and Mizuno 2008), gelatin (Drury and Mooney 2003; Aubin et al. 2010; Nichol et al. 2010), hyaluronic acid (Drury and Mooney 2003; Burdick and Prestwich 2011), fibrin (Lutolf and Hubbell 2005; Ahmed et al. 2008), and alginate (Rowley et al. 1999; Drury and Mooney 2003) have been explored for their use as the (bio)inks. While the properties of the synthetic materials (e.g., surface chemistry, mechanics, and degradation) can be conveniently tuned for a variety of applications, they typically are inert and lack bioactivity. On the contrary, the major advantage of natural polymers lies in their possession of specific ligands (e.g., RGD) that promote cell adhesion. Nevertheless, their applications have been limited by the poorly defined chemistry and variability among batches of production. Recently, decellularized ECMs (dECMs), a novel class of naturally derived composite biomate- rials, have attracted increasing attention for their use as bioinks (Murphy and Atala 2014; Pati et al. 2014; Stanton et al. 2015). One unique advantage of the dECMs not comparable by other bioinks lies in the ability to apply materials from the same tissues of interest during the bioprinting process, which promises to present well-matched compositional complexity in addition to architectural fidelity between the bioprinted biological structures and the targeting tissues (Murphy and Atala 2014; Stanton et al. 2015).

Besides biomaterials, encapsulated cells comprise another critical component of the bioinks. Similarly, the cells should also possess certain properties to ensure efficient bioprinting. For example, cells can be encapsulated in biomaterials as either individually dispersed cells or as aggregates (e.g., spheroids) (Bhise et al. 2015). While single-cell bioprinting allows for higher flexibility in producing tissues on smaller scales, direct bioprinting of spheroids could potentially reduce the time of fabricating larger tissues. In addition, better cell viability may be achieved when spheroids are used because of the protection of cells in the interiors of spheroids from the shear stress. In terms of cell source, terminally differentiated cells are most commonly used because of their wide availability, ease of maintenance, large quantities, and well-characterized functionalities. Nevertheless, with the development and maturation of the stem cell technologies in the past decade along with the progressively recognized versatility of their pluripotency or multipotent properties (Nombela-Arrieta et al. 2011; Robinton and Daley 2012; Yamanaka 2012), these cells have gradually entered into the arena of bioprinting (Ali et al. 2014; Faulkner-Jones et al. 2015). In a sense, bioprinting of stem cells combined with incorporation of properly localized biochemi$\mathrm{cal} /$ biophysical cues may greatly improve the outcome of engineered tissues and endow them with better functionality than those produced with already differentiated cells, due to the presence of mixed cell populations in native tissues.

After the bioinks have been determined, it is then necessary to choose a proper bioprinting 
technique for the fabrication of the final tissue constructs. Various representative bioprinting approaches include inkjet printing (Fig. 1B) such as piezo inkjet printing and thermal inkjet printing (Xu et al. 2005, 2013; Cui et al. 2012), microextrusion (Fig. 1C) (Cohen et al. 2006; Iwami et al. 2010), and laser-assisted forward transfer (Fig. 1D) (Barron et al. 2004; Guillotin et al. 2010). Piezo inkjet printing is able to dispense droplets of cell suspensions on demand, in which variations in the electric impulse and amplitude for activation of the piezoelectric actuator can be used to control the stress to which the bioink is exposed. Thermal inkjet printing on the other hand is operating through localized heating to achieve droplet dispensing. In both cases, the stages in which the bioinks are deposited move in the $z$-axis to collect 3D objects. Inkjet printing methods in general are cost-efficient and fast, but are limited by the fact that the bioink has to be in a relatively low-viscosity form to enable droplet formation and thus low cell concentration $\left(<10^{6}\right.$ cells $\left.\mathrm{mL}^{-1}\right)$ (Murphy and Atala 2014). Microextrusion is the most common form of material-dispensing technique used for bioprinting. Different from inkjet printing, microextrusion bioprinters operate through controlled extrusion of the bioinks by means of pneumatic pressure or mechanical compressions. Because of the singlenozzle feature, the stages (and/or the nozzles) for microextrusion bioprinters need to be capable of movement along all three axes to render it possible to create $3 \mathrm{D}$ tissues. Microextrusion bioprinters confer medium cost and the ability to encapsulate high densities of cells including spheroids, but the printing speeds are relatively low (Murphy and Atala 2014). Laser-assisted bioprinting relying on forward transfer has also been increasingly applied to the fabrication of tissues. In laser-assisted bioprinting, a ribbon carrying a photoabsorbing layer on the top side and a bioink layer at the bottom is illuminated by a focused laser beam; the positions hit by the laser will endure localized heating that facilitates the formation of bubbles and propel the bioink toward the stage, which moves along the $z$-axis for forming $3 \mathrm{D}$ constructs. The process is typically fast, enabling medium-to-high density of cells, which in turn renders the hardware cost higher than other forms of the bioprinters (Murphy and Atala 2014).

In the last step post-bioprinting, the engineered tissues or organs will further be maturated, usually through the use of perfusion bioreactors that provide excellent nutrient transport and physiological stimuli, before they are applied in vivo to regenerate their corresponding counterparts (Godbey and Atala 2002; Murphy and Atala 2013). Alternatively, engineered miniature tissues and organoids have also recently found ways in functioning as in vitro models. These biomimetic models, when embedded in interconnected microfluidic bioreactors (together termed as organs-onchips), nicely reproduce the key aspects of both the biology and the physiology of the human system, therefore functioning as an enabling platform for screening pharmaceutical compounds (Selimović et al. 2013; Bhise et al. 2014; Polini et al. 2014; Zhang and Khademhosseini 2015).

\section{SACRIFICIAL BIOPRINTING}

Blood vessels present an indispensable component in maintaining the viability and functionality of engineered tissues and organs through their unique capacity in providing sufficient transport of oxygen and nutrients to the tissues (Nomi et al. 2002; Bae et al. 2012; Zhang et al. 2015). Many tissue-engineering strategies have been devised to promote the vascularization potential of the biomaterials and/or the tissue constructs, including, for example, the incorporation of angiogenic growth factors such as vascular endothelial growth factors (VEGFs), basic fibroblast growth factor (bFGF), and platelet-derived growth factor (PDGF) (Richardson et al. 2001; Nguyen et al. 2012), coculture with pericytes such as mesenchymal stem cells (MSCs) and smooth muscle cells (SMCs) (Kirkpatrick et al. 2011; Unger et al. 2015), as well as hypoxia induction (Oladipupo et al. 2011). These approaches have led to great success, particularly when the formations of microvascular networks are involved. However, the 
Y.S. Zhang et al.

capability to generate perfusable prevascularized tissues remains challenging.

To this end, the sacrificial bioprinting technology developed in the past few years has provided a convenient resolution to such a challenge because of its capability to fabricate interconnected microchannels of arbitrary geometries and connectivity (Miller et al. 2012; Bertassoni et al. 2014; Kolesky et al. 2014; Lee et al. 2014). Sacrificial bioprinting features four successive steps: (1) deposition of the sacrificial microfibrous bioink that will eventually become the microchannels; (2) casting of the hydrogel embedded with cells over the templating microfibers to construct the tissue block; (3) removal of the template through dissolution, temperature-induced phase change, or mechanical extraction; and (4) endothelialization of the microchannels with infused endothelial cells. A successful sacrificial bioink should possess properties including biocompatibility, meaning that the bioink should not exert cytotoxicity during the deposition and encapsulation process, as well as removability in the presence of cells, requiring that the conditions under which the bioink is removed should not affect the behavior of the encapsulated cells in the bulk hydrogel.

Several major categories of sacrificial bioinks have thus been developed based on these requirements. For example, Chen and coworkers bioprinted fibrous scaffolds using carbohydrate glass (Miller et al. 2012); these microfibers were mechanically stable enough to support the subsequent casting and gelation of the matrix, but could be rapidly dissolved when the construct was immersed in the culture medium. Lewis and colleagues found that Pluronic F127 solution within a certain concentration range behaves as a shear-thinning gel at elevated temperature, but liquefies when the temperature approaches $0^{\circ} \mathrm{C}$ (Fig. 2A) (Kolesky et al. 2014). Such a property allows for maintenance of the cylindrical shape of the bioprinted bioink and the embedding process at room temperature, and possibility to wash out the liquefied sacrificial bioink by lowering the temperature. Using a combination of Pluronic F127 sacrificial bioink and regular bioinks, multilayer vascular- ized tissue constructs could be produced (Fig. 2B,C). Similarly, Dai and coworkers took advantage of the phase-changing property of gelatin, a biocompatible material, as the bioink for creation of perfusable vascular channels (Lee et al. 2014). Exactly like Pluronic F127 but reversed in phase, the gelatin solution $(>10 \%)$ forms a gel at room temperature or lower and changes back to the solution phase at $37^{\circ} \mathrm{C}$, which enables spontaneous dissolution of the liquefied bioink over the subsequent cell culture process.

Mechanical extraction of the templating microfibers from fabricated tissue blocks has also been shown to be efficient. In this case, Khademhosseini and colleagues adopted the phasechanging agarose solution as the sacrificial template (Fig. 2D) (Bertassoni et al. 2014). Agarose solution is in the liquid form at temperatures of $>80^{\circ} \mathrm{C}$; it solidifies with a strong mechanical strength when cooled down to room temperature, which allows these microfibers to be easily extracted manually or using a mild vacuum, leaving hollow channels that could be endothelialized later on. Hydrogel blocks containing different forms of interconnected vascular network were fabricated based on this versatile approach (Fig. 2E). Endothelialization is typically achieved by infusing high concentrations of endothelial cells in a medium into the bioprinted microchannel networks. By properly controlling the conditions for the seeding process, endothelial cells could form well-stretched monolayers in the inner surface of the channels mimicking the intact endothelium (Fig. 2F).

\section{HYDROGEL-EMBEDDED BIOPRINTING}

One major limitation with conventional extrusion-based bioprinting lies in their inability to deposit discrete layers that are not mechanically supported by those underneath. As a consequence, a new class of $3 \mathrm{D}$ bioprinting techniques have been developed, which permit direct printing of hydrogel bioinks into self-healing support hydrogels, allowing fabrication of discrete patterns in the volumetric space over relatively large scales. By design, either the deposited patterns in the hydrogel blocks can be sacrificially removed, 


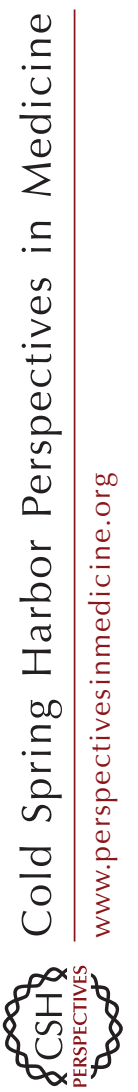

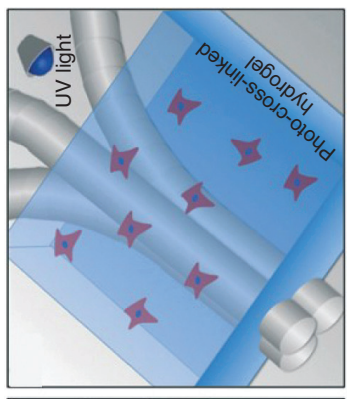
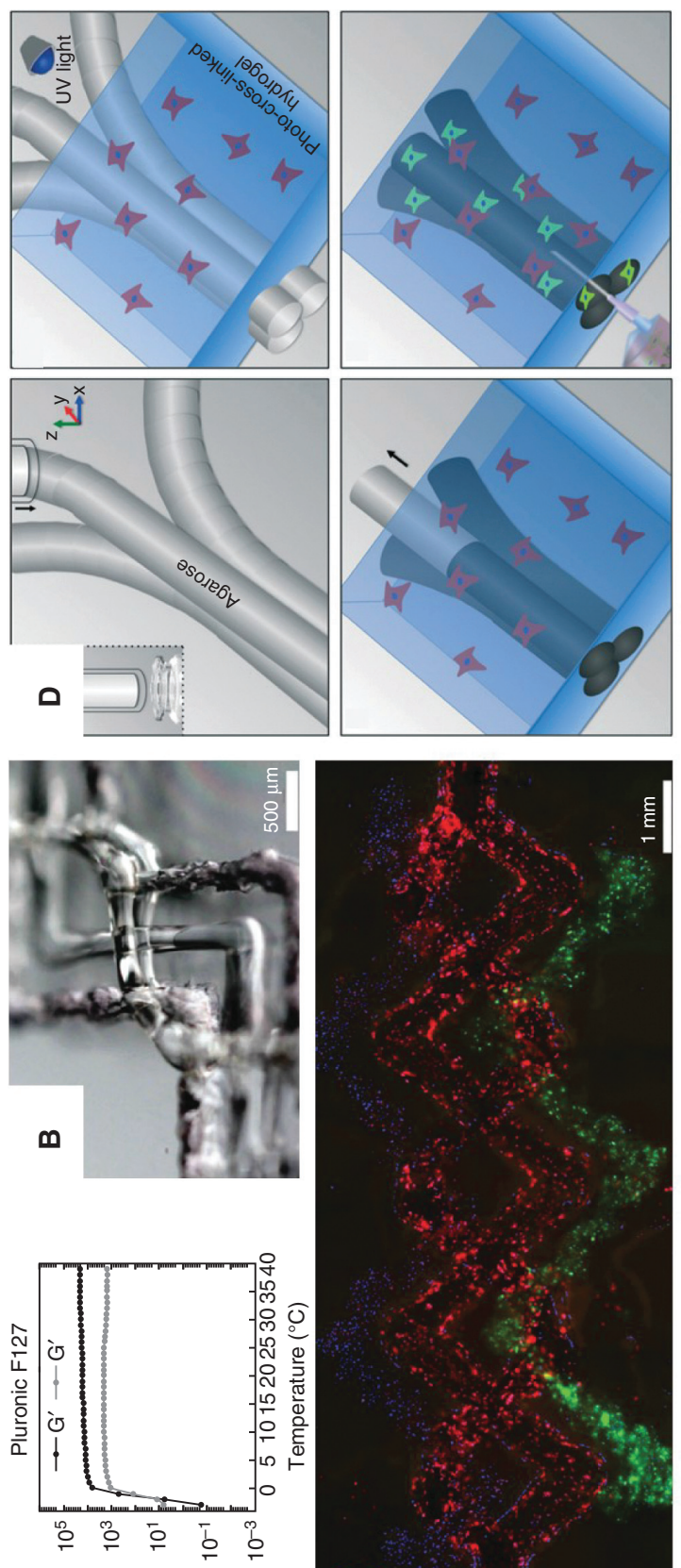

(ed) !npou גeәus

$\leftarrow$
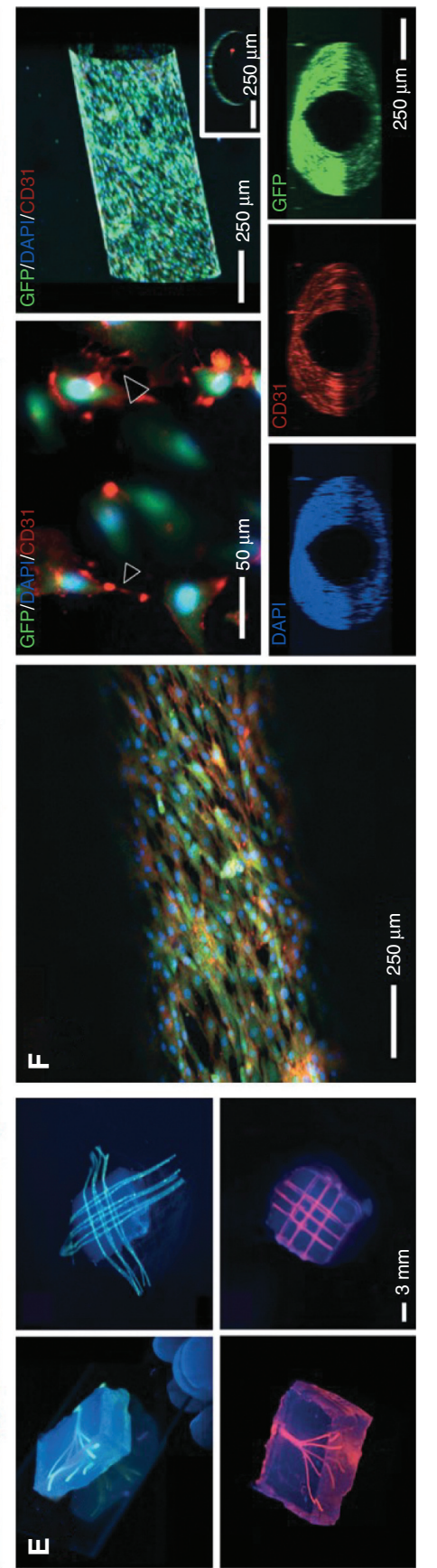

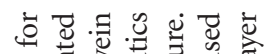

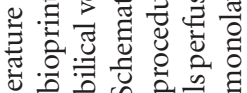

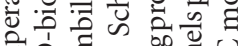

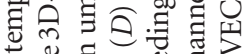

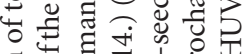

ธ。

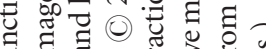

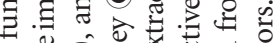



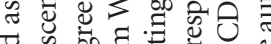

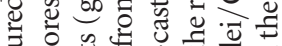

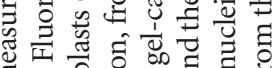

更

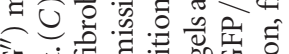

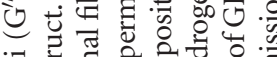

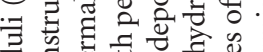

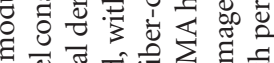

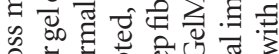

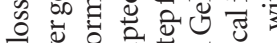

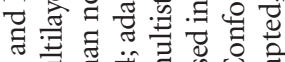

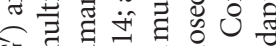

Ð

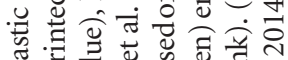

要

कै है है है त

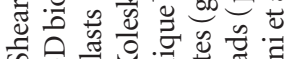

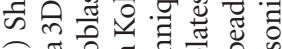

ङ

o0 品兄运

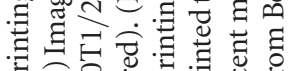

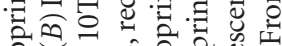

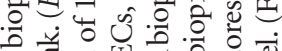

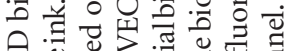

ल.

जo

击 0

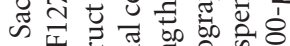

ن.

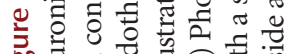

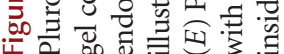


Y.S. Zhang et al.

leaving desired cavities in the $3 \mathrm{D}$ space, or the support matrices may be washed off to leave only the bioprinted 3D structures. For example, Burdick and coworkers developed the bioinks and the support hydrogels both based on supramolecular assembly through the guest-host system (Highley et al.2015). Because of the noncovalent bonding of the guest-host molecules, it allowed for disruption of the bonds when an external stimulus was applied such as shear stress (in the case of the bioinks) or deformation (in the case of the support matrices), which could then rapidly self-heal upon removal of the stimulus. Specifically, the supramolecular hydrogels were prepared based on modification of hyaluronic acid (HA) with either adamantine (Ad, guest) or $\beta$-cyclodextrin ( $\beta$-CD, host) (Ad-HA and CD-HA). The intermolecular guest-host bonds between Ad and $\beta-C D$ rendered the modified HAs the capability to self-assemble on mixing, which allowed for direct, supported bioprinting of 3D tissue architectures (Fig. 3A). Using such a technique, supramolecular filaments with varying diameters could be deposited in the support hydrogel by adjusting the size of the nozzle, the volume of the extruded bioinks, or the physical properties of the hydrogels (Fig. 3B). The guest-host writing further enabled bioprinting of discrete 3D structures not attainable by standard methods, such as the creation of a spiral structure surrounding a cylinder in the center (Fig. 3C). Significantly, these supramolecular hydrogels could also be designed to possess a secondary moiety that facilitates covalent cross-linking on demand to stabilize the bioprinting 3D structures. Burdick and coworkers introduced photo-cross-linkable methacrylate groups into the Ad-HA (Ad-MeHA) and CDHA (CD-MeHA), which could be used as either the bioinks or the support matrices, to selectively stabilize one of these two components depending on the requirement. As illustrated in Figure 3D, the Ad-MeHA/CD-MeHA was used as the support hydrogel; after bioprinting of the bifurcation microchannel using Ad-HA/CDHA bioink, the support hydrogel was ultraviolet (UV) cross-linked to permanently stabilize the construct followed by vacuum removal of the bioink to form the hollow, perfusable chan- nels. On the contrary, when the Ad-MeHA/CDMeHA hydrogel was used as the bioink, crosslinked 3D objects could be produced by dissolving the support matrix (Fig. 3E). The method has been reported to exert no negative effect on embedded cells.

Similarly, Feinberg and colleagues used a slurry of gelatin microparticles, processed to possess a shear-thinning property, as a support bath to enable direct deposition of bioinks in complex 3D structures (Hinton et al. 2015). The thermoreversibility of the gelatin support bath could then be selectively removed by elevating the temperature to $37^{\circ} \mathrm{C}$ to retrieve the printed biomimetic tissues. Angelini and colleagues adopted a similar idea by using a soft granular gel made from micrometer-sized soft hydrogel particles that smoothly transitions between fluid and solid states, as the support medium. The medium is fluidized under locally applied low shear stresses permitting direct writing of the bioinks, and rapidly resolidifies when the stresses are relocated, allowing for continuous bioprinting of 3D shapes (Bhattacharjee et al. 2015). If necessary, subsequent removal of the support gel could retrieve the bioprinted constructs. In another approach, Christensen (Christensen et al. 2015) took advantage of the physical crosslinking mechanism of alginate by $\mathrm{Ca}^{2+}$, and directly dispensed alginate droplets into a bath of $\mathrm{CaCl}_{2}$ solution to bioprint hollow bifurcation structures supported by the cross-linking bath.

\section{MULTIMATERIAL BIOPRINTING}

Biological tissues contain a mixture of different components arranged in well-defined architectures. Therefore, the capability to deposit more than one bioink has become an important aspect of bioprinting. Microfluidics has been increasingly used in the field of 3D bioprinting because of its versatility in switching between the liquid-like bioinks. Based on such a concept, Lewis, Khademhosseini, and their respective colleagues have recently reported two similar but complimentary techniques (Colosi et al. 2015; Hardin et al. 2015) for controlled printing of two unique materials either individually or simultaneously. 
A
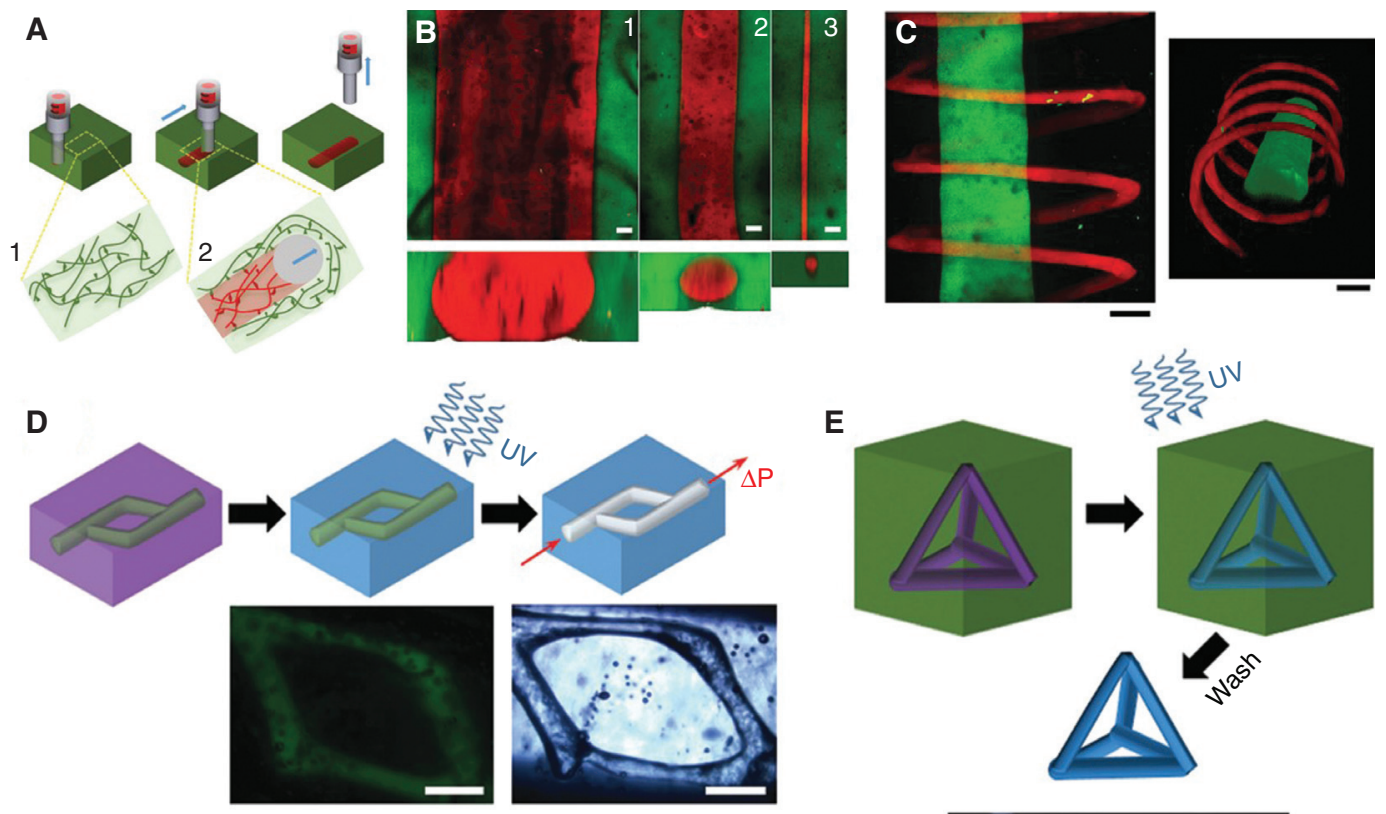

$\operatorname{ros}^{2} \operatorname{ros}_{2}$

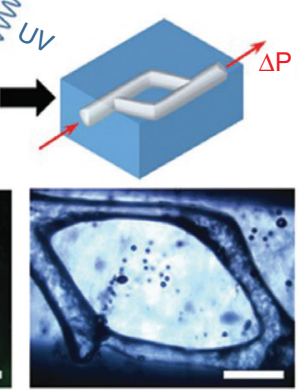

E
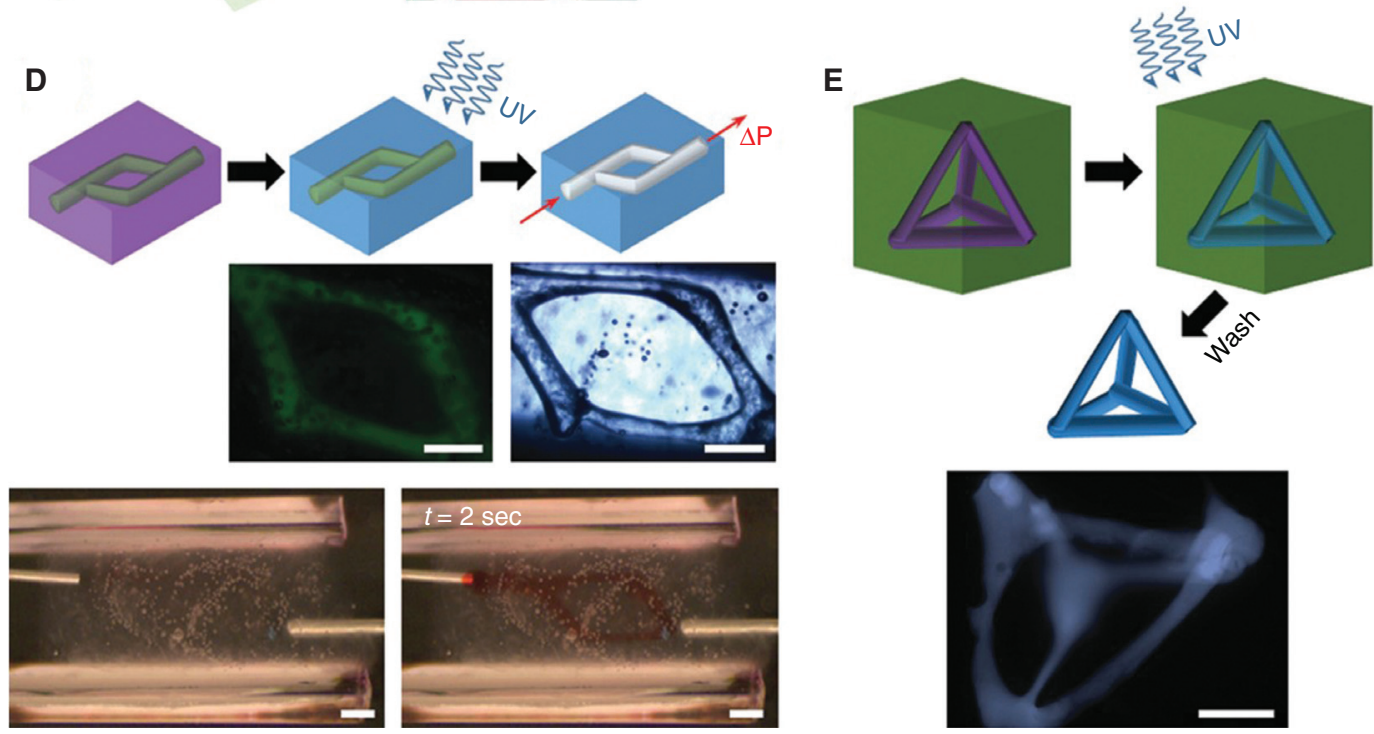

Figure 3. Hydrogel-supported 3D bioprinting. (A) Schematic illustration of the extrusion of a supramolecular ink (red) into a supramolecular support gel (green), in which (1) the undisturbed network (2) receives the printed ink. (B) Rhodamine-labeled filaments (red) extruded into a fluorescein-labeled support gel (green) from (1) 20G, (2) 27G, and (3) $34 \mathrm{G}$ needles. Scale bars, $100 \mu \mathrm{m}$. (C) Confocal images of a filament of a fluorescein-labeled ink (green) and a continuous spiral of a second rhodamine-labeled ink (red) printed into an unlabeled support gel. Scale bars, $200 \mu \mathrm{m}$. (D) The bioprinting of microchannels, by writing an ink into a support gel modified for secondary cross-linking. UV irradiation covalently cross-links the support gel, and pressure-driven flow resulted in removal of the ink, leaving a microchannel network. (Bottom) Images of channel perfusion with a red dye solution at 0 sec and $2 \mathrm{sec}$. Scale bars, $500 \mu \mathrm{m}$. (E) The bioprinting of self-supporting structures, by writing an ink that can be covalently cross-linked into a support gel, followed by UV cross-linking, and dissolution of the support with excess $\beta$-CD. Scale bar, $500 \mu \mathrm{m}$. (From Highley et al. 2015; adapted, with permission, from Wiley (C) 2015.)

Lewis and coworkers adapted a carefully designed microfluidic printhead with a pair of embedded hydraulic extruders to achieve selective dispensing of different materials (Fig. 4A) (Hardin et al. 2015). The on-demand actuation of the two channels resulted in the printing of multidimensional architectures composed of viscoelastic inks of varying composition as well as mechanical properties (Fig. 4B). Khademhosseini and coworkers further developed a microfluidic printhead for bioprinting of low-viscosity biocompatible inks (Fig. 4C) (Colosi et al. 2015). Specifically for this application, they optimized a composite bioink composed of gelatin methacryloyl (GelMA) and alginate, which could be initially physically cross-linked for the alginate component during the extrusion process to render structural stability of the constructs, whereas the GelMA component could be subsequently 
Y.S. Zhang et al.

A

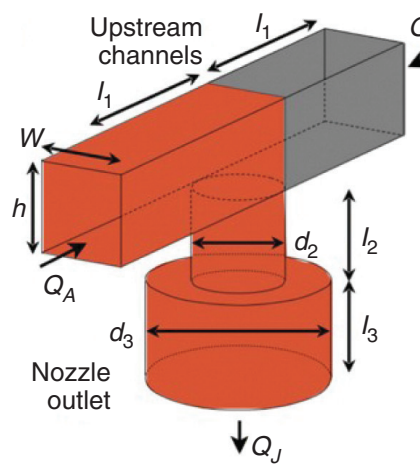

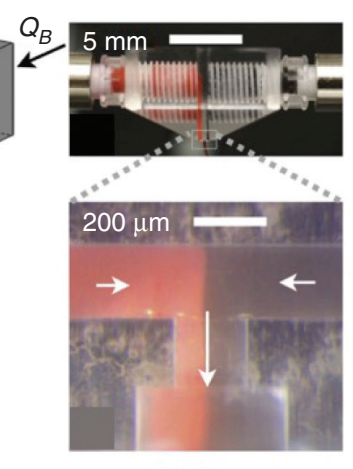

B

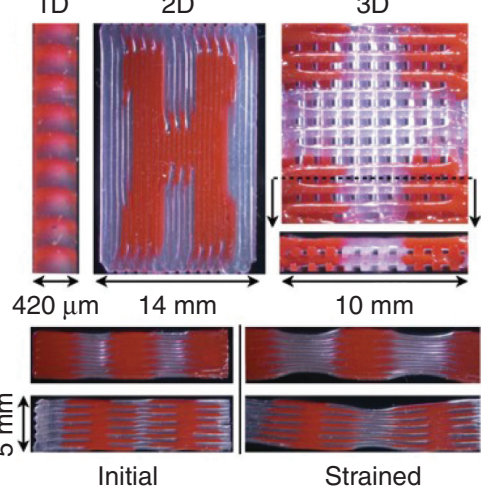

C

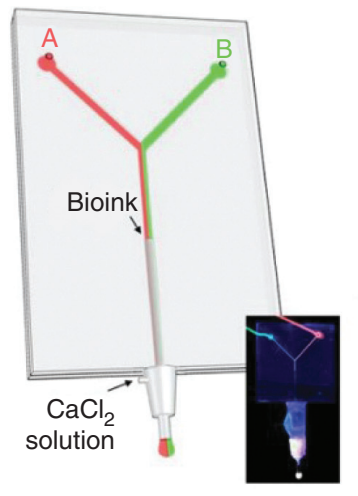

D

E
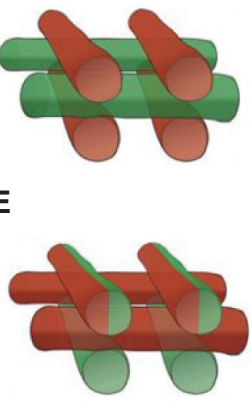

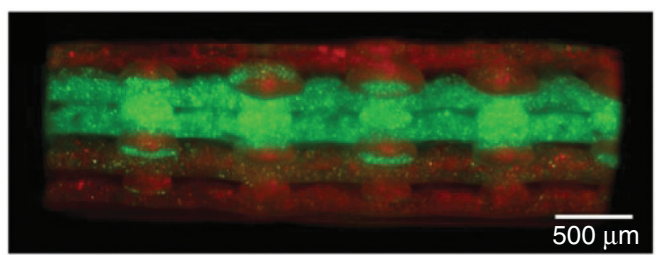

$\mathbf{F}$
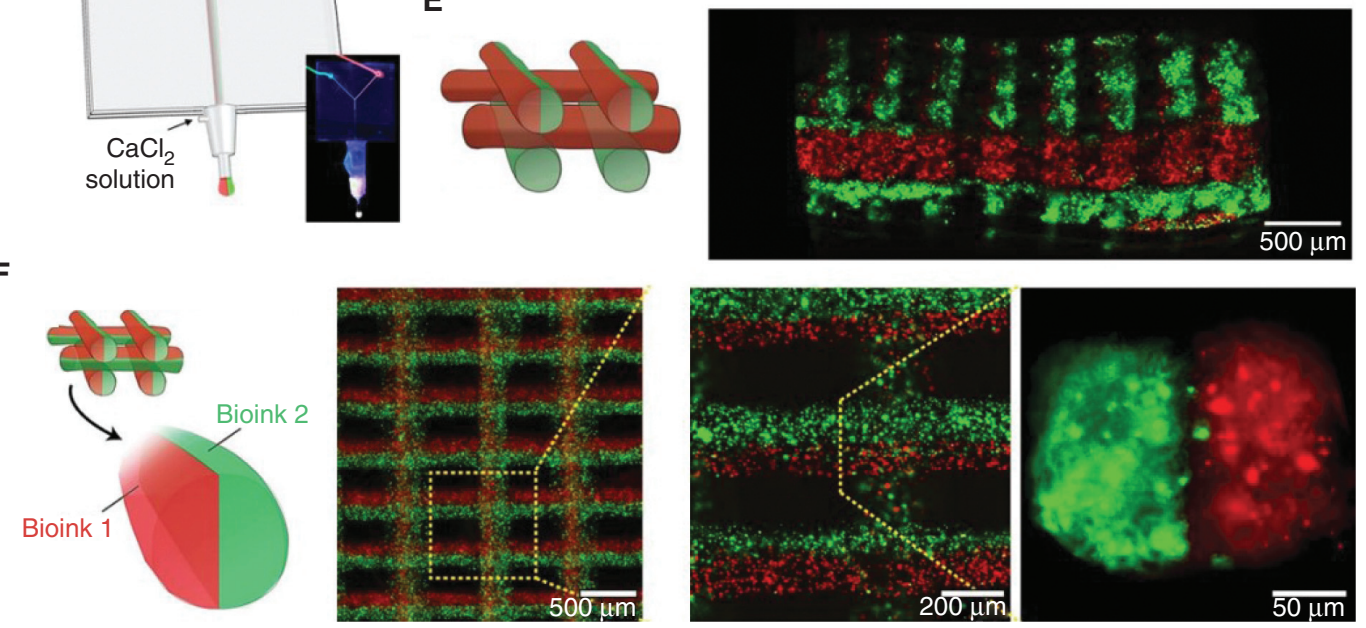

Figure 4. Multimaterial 3D bioprinting. (A) Schematic illustration of the dual-material microfluidic printhead. Two independently actuated syringe pumps controlled the flow of each material through the nozzle. (B) Printed dual-material multidimensional structures. (From Hardin et al. 2015; adapted, with permission, from Wiley (C) 2015.) (C) Schematic of a microfluidic system used to flow two separate bioinks that exited the device through a single extruder. $(D-F)$ Schematic diagrams and fluorescence microscopy images of a cross-sectional view of 3D constructs with $(D)$ alternative deposition, $(E)$ alternative/simultaneous deposition, and $(F)$ simultaneous deposition. (From Colosi et al. 2015; adapted, with permission, from the authors.)

chemically cross-linked by UV illumination to permanently fix the shape of the tissues. The alginate present in the bioprinted structures may be removed using a $\mathrm{Ca}^{2+}$ chelating agent, such as ethylenediaminetetraacetic acid (EDTA), to minimize its negative effects on the stretching and proliferation of the embedded cells. Alternative or simultaneous deposition of the bioinks using this microfluidic printhead allowed for convenient fabrication of 3D multicomponent tissue constructs of interest (Fig. 4D-F). 

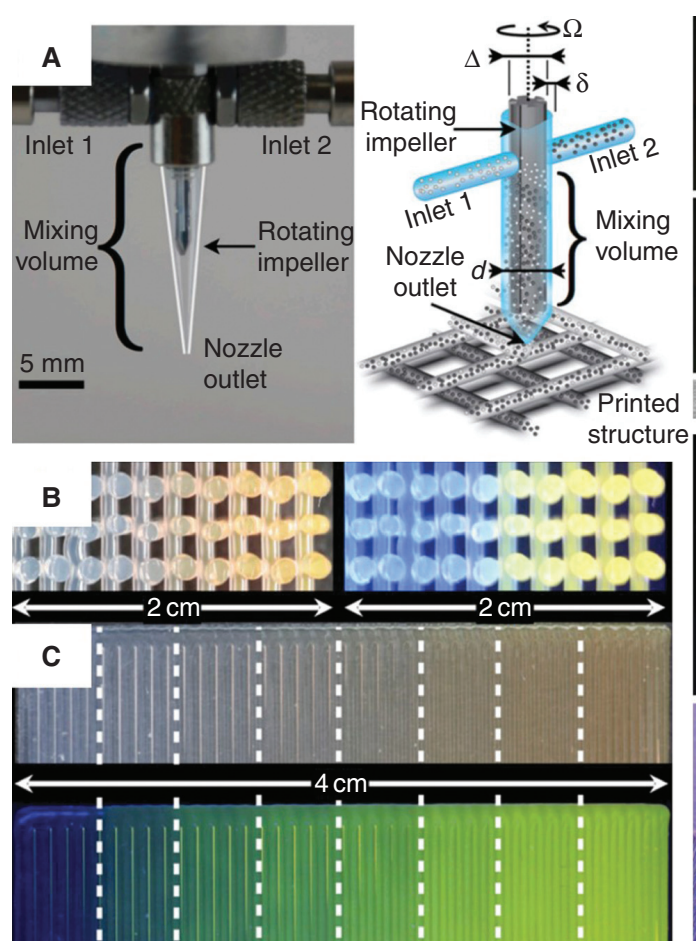

Figure 5. Gradient and high-throughput 3D bioprinting. (A) Photograph and schematic of a printhead based on the impeller-assisted active mixer. Each fluid enters the mixing chamber of diameter $d$ through a separate inlet and is homogenized in a narrow gap of width $\delta$ by an impeller of diameter $\Delta$ rotating at a constant rate $\Omega$. (B) Images of the cross-section of a 3D rectangular lattice structure showing continuous change in the concentration of fluorescent pigment under bright light (left) and UV radiation (right). $(C)$ Images of a 2D carpet structure showing a discretely varying fluorescent gradient at eight different mixing ratios under bright light (top) and UV radiation (bottom). Dashed white lines have been added to mark the regions of different mixing ratios. (From Ober et al. 2015; adapted, with permission, from National Academy of Sciences.) (D) Schematics showing the high-throughput microvascular multinozzle printhead containing a hierarchical microvascular channel network milled into an acrylic block, which was then solvent-welded to a nonpatterned acrylic block to form an embedded microvascular structure within a monolithic block. Optical micrograph at the bottom shows a 64nozzle array composed of square nozzles $(200 \mu \mathrm{m} \times 200 \mu \mathrm{m})$ with a $400-\mu \mathrm{m}$ center-to-center spacing. Scale bars, $2 \mathrm{~mm}$. (E) Photograph of the printhead filled with two inks fed by one ink inlet above (blue) and the other ink inlet below (yellow). Scale bar, $5 \mathrm{~mm}$. The bottom images show a printed multilayer structure composed of alternating wax filaments (the inset indicates a magnified view of a single-layer region; scale bar, $2 \mathrm{~mm}$ ), and a coprinted structure composed of wax ink filaments infilled with a photocurable epoxy resin (the inset indicates the cross-section of a fully cured 10-layer structure with the fugitive wax ink removed; scale bar, $1 \mathrm{~mm}$ ). Scale bars, $5 \mathrm{~mm}$. (From Hansen et al. 2013; adapted, with permission, from Wiley (C) 2013.)

\section{GRADIENT BIOPRINTING}

Certain tissues in the body present pronounced gradient in ECM compositions and/or cell populations, particularly for those at the interfaces such as the osteochondral interface, the ligament-to-bone interface, and the tendon-tobone insertion site. Conventional methods rely on the use of anisotropic scaffolds containing distinctive or continual sections with properties matching those in the native tissues to be engineered (Spalazzi et al. 2006; Wang et al. 2007; Li et al. 2009; Lu et al. 2010; Xie et al. 2010; Smith et al. 2012; Lu and Thomopoulos 2013; Liu et al. 2014; Atesok et al. 2016). Despite success, precise reproduction of the continuous 
Y.S. Zhang et al.

gradients in the chemical composition, materials properties, or the cell types has hardly been achieved before because of limitations associated with manufacturing. In fact, the continuous extrusion process during the bioprinting has provided an excellent basis for realizing such a gradient in $3 \mathrm{D}$ volumes, when combined with the aforementioned multimaterial microfluidic nozzle platform.

By incorporating a rotating impeller into the central channel of their developed two-way microfluidic printhead, Lewis and colleagues were able to achieve rapid and thorough mixing of the two inks on contact before extruding the microfibers to form the printed structures (Fig. 5A) (Ober et al. 2015). By carefully tuning the volume ratio of the two bioinks it was possible to fabricate $3 \mathrm{D}$ constructs or $2 \mathrm{D}$ patterns with continuous gradient of encapsulated chemicals and/or material properties (Fig. 5B,C). Although a preliminary demonstration without biological components, such a technique is fully compatible with bioinks and cells, which will eventually enable bioprinting of functional gradient constructs for regenerating tissues particularly those at the interfaces.

\section{CONCLUDING REMARKS}

While a rich variety of 3D bioprinting techniques have been innovated to enable reproduction of functional tissues and organs at a higherthan-ever fidelity and convenience, challenges still persist. Maintenance of the viability of cells encapsulated inside the bioinks poses a challenge. In addition, the bioinks should protect the cells from being damaged by the potentially high shear stress during the extrusion process. Precision of the bioprinted structures may be compromised at corners particularly when using the microfluidic printhead in which transient fluctuations in the pressures caused by sharp changes in flow rates may be present (Hardin et al. 2015). Therefore, meticulous design of the hardware and bioinks should be conducted to avoid these effects. The speed of bioprinting is another concern that may eventually influence the viability and functionality of the final engineered tissues/organs. A method based on microvascular multinozzle printing was thus proposed to fabricate large-scale constructs of multiple components or with hollow structures in a high-throughput manner (Fig. 5D,E) (Hansen et al. 2013), potentially minimizing the time needed for tissue/organ production. We believe that further advancements in $3 \mathrm{D}$ bioprinting technologies in the near future will undoubtedly propel the field of tissue engineering to a new height by enabling complex tissue fabrication and patient-driven precision medicine.

\section{ACKNOWLEDGMENTS}

The authors gratefully acknowledge funding by the Office of Naval Research Young National Investigator Award, the National Institutes of Health (EB012597, AR057837, DE021468, HL099073, R56AI105024, EB021148, EB 021857), and the Presidential Early Career Award for Scientists and Engineers (PECASE). Y.S.Z. acknowledges the National Cancer Institute of the National Institutes of Health Pathway to Independence Award (K99CA201603). The publication of this material does not constitute approval by the government of the findings or conclusions herein.

\section{REFERENCES}

Ahmed TA, Dare EV, Hincke M. 2008. Fibrin: A versatile scaffold for tissue engineering applications. Tissue Eng B 14: 199-215.

Ali M, Pages E, Ducom A, Fontaine A, Guillemot F. 2014. Controlling laser-induced jet formation for bioprinting mesenchymal stem cells with high viability and high resolution. Biofabrication 6: 045001.

Allard TT, Sitchon M, Sawatzky R, Hoppa R. 2005. Use of hand-held laser scanning and 3D printing for creation of a museum exhibit. In Proceedings of the 6th International Symposium on Virtual Reality, Archaeology and Cultural Heritage: Short and Project Papers (ed. Mudge M, Ryan N, Scopigno R, et al.), pp. 97-101.

Atesok K, Doral MN, Karlsson J, Egol KA, Jazrawi LM, Coelho PG, Martinez A, Matsumoto T, Owens B, Ochi M, et al. 2016. Multilayer scaffolds in orthopaedic tissue engineering. Knee Surg Sports Traumatol Arthrosc 24: 2365-2373.

Aubin H, Nichol JW, Hutson CB, Bae H, Sieminski AL, Cropek DM, Akhyari P, Khademhosseini A. 2010. Directed $3 \mathrm{D}$ cell alignment and elongation in microengineered hydrogels. Biomaterials 31: 6941-6951. 
Bae H, Puranik AS, Gauvin R, Edalat F, Carrillo-Conde B, Peppas NA, Khademhosseini A. 2012. Building vascular networks. Sci Transl Med 4: 160ps123.

Barron JA, Wu P, Ladouceur HD, Ringeisen BR. 2004. Biological laser printing: A novel technique for creating heterogeneous 3-dimensional cell patterns. Biomed Microdevices 6: 139-147.

Bertassoni LE, Cecconi M, Manoharan V, Nikkhah M, Hjortnaes J, Cristino AL, Barabaschi G, Demarchi D, Dokmeci MR, Yang Y. 2014. Hydrogel bioprinted microchannel networks for vascularization of tissue engineering constructs. Lab Chip 14: 2202-2211.

Bhattacharjee T, Zehnder SM, Rowe KG, Jain S, Nixon RM, Sawyer WG, Angelini TE. 2015. Writing in the granular gel medium. Sci Adv 1: e1500655.

Bhise NS, Ribas J, Manoharan V, Zhang YS, Polini A, Massa S, Dokmeci MR, Khademhosseini A. 2014. Organ-on-achip platforms for studying drug delivery systems. J Controlled Release 190: 82-93.

Bhise NS, Manoharan V, Massa S, Tamayol A, Ghaderi M, Miscuglio M, Lang Q, Zhang YS, Shin SR, Calzone G, et al. 2015. A liver-on-a-chip platform with bioprinted hepatic spheroids. Biofabrication 8: 014101.

Burdick JA, Prestwich GD. 2011. Hyaluronic acid hydrogels for biomedical applications. Adv Mater 23: H41-H56.

Cen L, Liu W, Cui L, Zhang W, Cao Y. 2008. Collagen tissue engineering: Development of novel biomaterials and applications. Pediatr Res 63: 492-496.

Christensen K, Xu C, Chai W, Zhang Z, Fu J, Huang Y. 2015. Freeform inkjet printing of cellular structures with bifurcations. Biotech Bioeng 112: 1047-1055.

Cohen DL, Malone E, Lipson HOD, Bonassar LJ. 2006. Direct freeform fabrication of seeded hydrogels in arbitrary geometries. Tissue Eng 12: 1325-1335.

Colosi C, Shin SR, Manoharan V, Massa S, Constantini M, Barbetta A, Dokmeci MR, Dentini M, Khademhosseini A. 2015. Microfluidic bioprinting of heterogeneous 3D tissue constructs using low viscosity bioink. Adv Mater 28: 677-684.

Cui X, Boland T, D'Lima DD, Lotz MK. 2012. Thermal inkjet printing in tissue engineering and regenerative medicine. Recent Pat Drug Deliv Formul 6: 149-155.

Drury JL, Mooney DJ. 2003. Hydrogels for tissue engineering: Scaffold design variables and applications. Biomaterials 24: $4337-4351$.

Du Y, Lo E, Ali S, Khademhosseini A. 2008. Directed assembly of cell-laden microgels for fabrication of 3D tissue constructs. Proct Natl Acad Sci 105: 9522-9527.

Du Y, Ghodousi M, Qi H, Haas N, Xiao W, Khademhosseini A. 2011. Sequential assembly of cell-laden hydrogel constructs to engineer vascular-like microchannels. Biotechnol Bioeng 108: 1693-1703.

Faulkner-Jones A, Fyfe C, Cornelissen D-J, Gardner J, King J, Courtney A, Shu W. 2015. Bioprinting of human pluripotent stem cells and their directed differentiation into hepatocyte-like cells for the generation of mini-livers in 3D. Biofabrication 7: 044102

Freed LE, Vunjak-Novakovic G, Biron RJ, Eagles DB, Lesnoy DC, Barlow SK, Langer R. 1994. Biodegradable polymer scaffolds for tissue engineering. Nat Biotechnol 12: 689 693.
Freed LE, Engelmary GCJR, Borenstein JT, Moutos FT, Guilak F. 2009. Advanced material strategies for tissue engineering scaffolds. Adv Mater 21: 3410-3418.

Gering DT, Nabavi A, Kikinis R, Hata N, O’Donnell LJ, Grimson WEL, Jolesz FA, Black PM, Wells WM. 2001. An integrated visualization system for surgical planning and guidance using image fusion and an open MR. $J$ Magn Reson Imaging 13: 967-975.

Glowacki J, Mizuno S. 2008. Collagen scaffolds for tissue engineering. Biopolymers 89: 338-344.

Godbey WT, Atala A. 2002. In vitro systems for tissue engineering. Ann NY Acad Sci 961: 10-26.

Guillotin B, Souquet A, Catros S, Duocastella M, Pippenger B, Bellance S, Bareille R, Rémy M, Bordenave L, Amédée J. 2010. Laser assisted bioprinting of engineered tissue with high cell density and microscale organization. Biomaterials 31: 7250-7256.

Hansen CJ, Saksena R, Kolesky DB, Vericella JJ, Kranz SJ, Muldowney GP, Christensen KT, Lewis JA. 2013. Highthroughput printing via microvascular multinozzle arrays. Adv Mater 25: 96-102.

Hardin JO, Ober TJ, Valentine AD, Lewis JA. 2015. Microfluidic printheads for multimaterial 3D printing of viscoelastic inks. Adv Mater 27: 3279-3284.

Highley CB, Rodell CB, Burdick JA. 2015. Direct 3D printing of shear-thinning hydrogels into self-healing hydrogels. Adv Mater 27: 5075-5079.

Hinton TJ, Jallerat Q, Palchesko RN, Park JH, Grodzicki MS, Shue HJ, Ramadan MH, Hudson AR, Feinberg AW. 2015. Three-dimensional printing of complex biological structures by freeform reversible embedding of suspended hydrogels. Sci Adv 1: e1500758.

Hoffman AS. 2012. Hydrogels for biomedical applications. Adv Drug Del Rev 64: 18-23.

Huang D, Swanson EA, Lin CP, Schuman JS, Stinson WG, Chang W, Hee MR, Flotte T, Gregory K, Puliafito CA. 1991. Optical coherence tomography. Science 254: $1178-1181$.

Hull CW. 1986. Apparatus for production of three-dimensional objects by stereolithography. U.S. patent 4575330 A

Hutmacher DW. 2001. Scaffold design and fabrication technologies for engineering tissues-State of the art and future perspectives. J Biomater Sci Polym Ed 12: 107-124.

Iwami K, Noda T, Ishida K, Morishima K, Nakamura M, Umeda N. 2010. Bio rapid prototyping by extruding/ aspirating/refilling thermoreversible hydrogel. Biofabrication 2: 014108 .

Jeon O, Ryu SH, Chung JH, Kim BS. 2005. Control of basic fibroblast growth factor release from fibrin gel with heparin and concentrations of fibrinogen and thrombin. J Control Release 105: 249-259.

Khetan S, Guvendiren M, Legant WR, Cohen DM, Chen CS, Burdick JA. 2013. Degradation-mediated cellular traction directs stem cell fate in covalently crosslinked three-dimensional hydrogels. Nat Mater 12: 458-465.

Kirkpatrick CJ, Fuchs S, Unger RE. 2011. Co-culture systems for vascularization-Learning from nature. Adv Drug Del Rev 63: 291-299.

Kolesky DB, Truby RL, Gladman AS, Busbee TA, Homan KA, Lewis JA. 2014. 3D bioprinting of vascularized, het- 
Y.S. Zhang et al.

erogeneous cell-laden tissue constructs. Adv Mater 26: 3124-3130.

Lee VK, Kim DY, Ngo H, Lee Y, Seo L, Yoo SS, Vincent PA, Dai G. 2014. Creating perfused functional vascular channels using 3D bio-printing technology. Biomaterials 35: 8092-8102.

Leijten J, Rouwkema J, Zhang YS, Nasajpour A, Dokmeci MR, Khademhosseini A. 2015. Advancing tissue engineering: A tale of nano, micro and macro scale integration. Small 12: 2130-2145.

Li X, Xie J, Lipner J, Yuan X, Thomopoulos S, Xia Y. 2009. Nanofiber scaffolds with gradations in mineral content for mimicking the tendon-to-bone insertion site. Nano Lett 9: 2763-2768.

Liu W, Thomopoulos S, Xia Y. 2012. Electrospun nanofibers for regenerative medicine. Adv Healthcare Mater 1: 10 25 .

Liu W, Lipner J, Xie J, Manning CN, Thomopoulos S, Xia Y. 2014. Nanofiber scaffolds with gradients in mineral content for spatial control of osteogenesis. ACS Appl Mater Interfaces 6: 2842-2849.

Lu HH, Thomopoulos S. 2013. Functional attachment of soft tissues to bone: Development, healing, and tissue engineering. Annu Rev Biomed Eng 15: 201.

Lu H, Subramony S, Boushell M, Zhang X. 2010. Tissue engineering strategies for the regeneration of orthopedic interfaces. Ann Biomed Eng 38: 2142-2154.

Lutolf M, Hubbell J. 2005. Synthetic biomaterials as instructive extracellular microenvironments for morphogenesis in tissue engineering. Nat Biotechnol 23: 47-55.

Lutolf MP, Lauer-Fields JL, Schmoekel HG, Metters AT, Weber FE, Fields GB, Hubbell JA. 2003. Synthetic matrix metalloproteinase-sensitive hydrogels for the conduction of tissue regeneration: Engineering cell-invasion characteristics. Proct Natl Acad Sci 100: 5413-5418.

Ma PX. 2004. Scaffolds for tissue fabrication. Mater Today 7: $30-40$.

Malda J, Visser J, Melchels FP, Jüngst T, Hennink WE, Dhert WJ, Groll J, Hutmacher DW. 2013. 25th anniversary article: Engineering hydrogels for biofabrication. $\mathrm{Adv} \mathrm{Ma}-$ ter 25: 5011-5028.

Malone E, Lipson H. 2007. Fab@Home: The personal desktop fabricator kit. Rapid Prototyping J 13: 245-255.

Mankovich NJ, Samson D, Pratt W, Lew D, Beumer JIII. 1994. Surgical planning using three-dimensional imaging and computer modeling. Otolaryngol Clin North Am 27: $875-889$.

Martino MM, Briquez PS, Ranga A, Lutolf MP, Hubbell JA. 2013. Heparin-binding domain of fibrin(ogen) binds growth factors and promotes tissue repair when incorporated within a synthetic matrix. Proct Natl Acad Sci 110: 4563-4568.

Michalski MH, Ross JS. 2014. The shape of things to come: 3D printing in medicine. JAMA 312: 2213-2214.

Miller JS, Stevens KR, Yang MT, Baker BM, Nguyen DHT, Cohen DM, Toro E, Chen AA, Galie PA, Yu X. 2012. Rapid casting of patterned vascular networks for perfusable engineered three-dimensional tissues. Nat Mater 11: $768-774$.

Murphy SV, Atala A. 2013. Organ engineering-combining stem cells, biomaterials, and bioreactors to produce bio- engineered organs for transplantation. Bioessays 35: 163 172.

Murphy SV, Atala A. 2014. 3D bioprinting of tissues and organs. Nat Biotechnol 32: 773-785.

Nguyen LH, Annabi N, Nikkhah M, Bae H, Binan L, Park S, Kang Y, Yang Y, Khademhosseini A. 2012. Vascularized bone tissue engineering: Approaches for potential improvement. Tissue Eng B 18: 363-382.

Nichol JW, Khademhosseini A. 2009. Modular tissue engineering: Engineering biological tissues from the bottom up. Soft Matter 5: 1312-1319.

Nichol JW, Koshy ST, Bae H, Hwang CM, Yamanlar S, Khademhosseini A. 2010. Cell-laden microengineered gelatin methacrylate hydrogels. Biomaterials 31: 5536-5544.

Nombela-Arrieta C, Ritz J, Silberstein LE. 2011. The elusive nature and function of mesenchymal stem cells. Nat Rev Mol Cell Biol 12: 126-131.

Nomi M, Atala A, Coppi PD, Soker S. 2002. Principals of neovascularization for tissue engineering. Mol Aspects Med 23: 463-483.

Ober TJ, Foresti D, Lewis JA. 2015. Active mixing of complex fluids at the microscale. Proct Natl Acad Sci 112: 12293 12298.

Oladipupo S, Hu S, Kovalski J, Yao J, Santeford A, Sohn RE, Shohet R, Maslov K, Wang LV, Arbeit JM. 2011. Vegf is essential for hypoxia-inducible factor-mediated neovascularization but dispensable for endothelial sprouting. Proct Natl Acad Sci 108: 13264-13269.

Owen SC, Shoichet MS. 2010. Design of three-dimensional biomimetic scaffolds. J Biomed Mater Res A 94A: 13211331.

Pan Z, Ding J. 2012. Poly(lactide-co-glycolide) porous scaffolds for tissue engineering and regenerative medicine. Interface Focus 2: 366-377.

Pati F, Jang J, Ha DH, Kim SW, Rhie JW, Shim JH, Kim DH, Cho DW. 2014. Printing three-dimensional tissue analogues with decellularized extracellular matrix bioink. Nat Commun 5: 3935.

Polini A, Prodanov L, Bhise NS, Manoharan V, Dokmeci MR, Khademhosseini A. 2014. Organs-on-a-chip: A new tool for drug discovery. Expert Opin Drug Discov 9: 335-352.

Purcell BP, Lobb D, Charati MB, Dorsey SM, Wade RJ, Zellars KN, Doviak H, Pettaway S, Logdon CB, Shuman JA, et al. 2014. Injectable and bioresponsive hydrogels for ondemand matrix metalloproteinase inhibition. Nat Mater 13: $653-661$.

Qi H, Ghodousi M, Du Y, Grun C, Bae H, Yin P, Khademhosseini A. 2013. DNA-directed self-assembly of shapecontrolled hydrogels. Nat Commun 4: 2275.

Richardson TP, Peters MC, Ennett AB, Mooney DJ. 2001. Polymeric system for dual growth factor delivery. Nat Biotechnol 19: 1029-1034.

Robinton DA, Daley GQ. 2012. The promise of induced pluripotent stem cells in research and therapy. Nature 481: 295-305.

Rowley JA, Madlambayan G, Mooney DJ. 1999. Alginate hydrogels as synthetic extracellular matrix materials. Biomaterials 20: 45-53. 
Selimović Š, Dokmeci MR, Khademhosseini A. 2013. Organs-on-a-chip for drug discovery. Curr Opin Pharmacol 13: $829-833$.

Smith L, Xia Y, Galatz LM, Genin GM, Thomopoulos S 2012. Tissue-engineering strategies for the tendon/ligament-to-bone insertion. Connect Tissue Res 53: 95-105.

Spalazzi JP, Doty SB, Moffat KL, Levine WN, Lu HH. 2006. Development of controlled matrix heterogeneity on a triphasic scaffold for orthopedic interface tissue engineering. Tissue Eng 12: 3497-3508.

Stanton MM, Samitier J, Sánchez S. 2015. Bioprinting of 3D hydrogels. Lab Chip 15: 3111-3115.

Symes MD, Kitson PJ, Yan J, Richmond CJ, Cooper GJT Bowman RW, Vilbrandt T, Cronin L. 2012. Integrated $3 \mathrm{D}$-printed reactionware for chemical synthesis and analysis. Nat Chem 4: 349-354.

Todhunter ME, Jee NY, Hughes AJ, Coyle MC, Cerchiari A, Farlow J, Garbe JC, LaBarge MA, Desai TA, Gartner ZJ. 2015. Programmed synthesis of three-dimensional tissues. Nat Methods 12: 975-981.

Unger RE, Dohle E, Kirkpatrick CJ. 2015. Improving vascularization of engineered bone through the generation of proangiogenic effects in co-culture systems. Adv Drug Deliv Rev 94: $116-125$

Wang LV. 2009. Multiscale photoacoustic microscopy and computed tomography. Nat Photon 3: 503-509.

Wang LV, Hu S. 2012. Photoacoustic tomography: In vivo imaging from organelles to organs. Science 335: 1458 1462.

Wang Y, Ameer GA, Sheppard BJ, Langer R. 2002. A tough biodegradable elastomer. Nat Biotechnol 20: 602-606.
Wang INE, Shan J, Choi R, Oh S, Kepler CK, Chen FH, Lu HH. 2007. Role of osteoblast-fibroblast interactions in the formation of the ligament-to-bone interface. J Orthop Res 25: 1609-1620.

Xie J, Li X, Lipner J, Manning CN, Schwartz AG, Thomopoulos S, Xia Y. 2010. "Aligned to random" nanofiber scaffolds for mimicking the structure of the tendon-tobone insertion site. Nanoscale 2: 923-926.

Xu T, Jin J, Gregory C, Hickman JJ, Boland T. 2005. Inkjet printing of viable mammalian cells. Biomaterials 26: $93-$ 99.

Xu T, Zhao W, Zhu JM, Albanna MZ, Yoo JJ, Atala A. 2013. Complex heterogeneous tissue constructs containing multiple cell types prepared by inkjet printing technology. Biomaterials 34: 130-139.

Yamanaka S. 2012. Induced pluripotent stem cells: Past, present, and future. Cell Stem Cell 10: 678-684.

Zhang YS, Khademhosseini A. 2015. Seeking the right context for evaluating nanomedicine: From tissue models in petri dishes to microfluidic organs-on-a-chip. Nanomedicine 10: 685-688.

Zhang YS, Xia Y. 2015. Multiple facets for extracellular matrix mimicking in regenerative medicine. Nanomedicine 10: 689-692.

Zhang YS, Choi SW, Xia Y. 2013. Inverse opal scaffolds for applications in regenerative medicine. Soft Matter 9: 9747-9754.

Zhang YS, Aleman J, Arneri A, Bersini S, Piraino F, Shin SR, Dokmeci MR, Khademhosseini A. 2015. From cardiac tissue engineering to heart-on-a-chip: Beating challenges. Biomed Mater 10: 034006. 


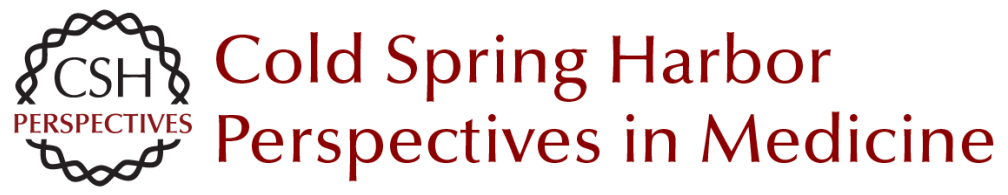

\section{Three-Dimensional Bioprinting Strategies for Tissue Engineering}

Yu Shrike Zhang, Rahmi Oklu, Mehmet Remzi Dokmeci and Ali Khademhosseini

Cold Spring Harb Perspect Med 2018; doi: 10.1101/cshperspect.a025718 originally published online March 13, 2017

\section{Subject Collection Tissue Engineering and Regenerative Medicine}

The Heart and Great Vessels

Ekene Onwuka, Nakesha King, Eric Heuer, et al.

Three-Dimensional Bioprinting Strategies for

Tissue Engineering

Yu Shrike Zhang, Rahmi Oklu, Mehmet Remzi

Dokmeci, et al.

Honing Cell and Tissue Culture Conditions for

Bone and Cartilage Tissue Engineering Johnny Lam, Esther J. Lee, Elisa C. Clark, et al.

Tissue Engineering Functional Gastrointestinal Regions: The Importance of Stem and Progenitor Cells

Andrew Trecartin and Tracy Grikscheit

\section{Historical Perspective and Future Direction of Blood Vessel Developments Sashka Dimitrievska and Laura E. Niklason \\ Craniofacial Tissue Engineering Weibo Zhang and Pamela Crotty Yelick}

The Self-Assembling Process and Applications in Tissue Engineering Jennifer K. Lee, Jarrett M. Link, Jerry C.Y. Hu, et al.

Biologic Scaffolds Alessandra Costa, Juan Diego Naranjo, Ricardo Londono, et al.

For additional articles in this collection, see http://perspectivesinmedicine.cshlp.org/cgi/collection/ 